\title{
The Importance of Heritability in Psychological Research: The Case of Attitudes
}

\begin{abstract}
Abraham Tesser
It is argued that differences in response heritability may have important implications for the testing of general psychological theories, that is, responses that differ in heritability may function differently. For example, attitudes higher in heritability are shown to be responded to more quickly, to be more resistant to change, and to be more consequential in the attitude similarity attraction relationship. The substantive results are interpreted in terms of attitude strength and niche building. More generally, the implications of heritability for the generality and typicality of treatment effects are also discussed.
\end{abstract}

Although psychologists clearly recognize the impact of genetics on behavior, their theories rarely reflect this knowledge. Most theories assume that behavior is relatively plastic and is shaped almost entirely by situational parameters. The possibility that a response may have a high heritability is often ignored. 1 argue here that ignoring this possibility is consequential. The vehicle used in this article is attitudes. This vehicle was chosen because it is a domain with which I have some familiarity; it is a domain that has a number of minitheories, and it is a domain in which the notion of heritability itself is suspect so that a demonstration of the effects of heritability should be particularly evocative.

\section{Background}

The notion that complex behavior may have genetic antecedents is not new. For example, Francis Galton (1875) studied the heritability of genius in the nineteenth century. Although the idea that genetics influences behavior went through a period of controversy, particularly with respect to race and intelligence, it is currently enjoying a new, high level of acceptance (Plomin \& Rende, 1991). For example, most social scientists now believe that intelligence test scores are significantly affected by genetics (Snyderman \& Rothman, 1987).

The list of behavioral domains that appear to have sizable

This research was supported by National Science Foundation Grant BNS-9016578.

The following people and organizations have made substantial contributions to this research: Rick Crelia did a masterful job of programming the experiments in which subjects interacted with a computer. Wallace Hwang did most of the analyses. The Survey Research Center (Jack Martin, Director) of the Institute for Behavioral Research, University of Georgia, recruited and ran the subjects for Study 3 and part of Study 1. Steve Smith helped design the questionnaire and ran the subjects for Study 2. David Ward ran some of the subjects for Study 1. This report benefited from comments by Wyatt Anderson, Steve Beach, Thomas Bouchard, and Len Martin.

Correspondence concerning this article should be addressed to Abraham Tesser, Institute for Behavioral Research, University of Georgia, Athens, Georgia 30602. heritabilities is both long and surprising. As noted earlier, the intellectual abilities domain has received the most press, and the genetic contribution to that domain is well documented (e.g., Loehlin, Willerman, \& Horn, 1988; Plomin \& Rende, 1991). There is also evidence of genetic contributions to specific cognitive abilities, school achievement, creativity, reading disability, and mental retardation (see Plomin, 1989, for a review). In the area of psychopathology, schizophrenia, affective disorders, alcoholism, antisocial personality, anorexia nervosa, infantile autism, Tourette's syndrome, and Alzheimer's disease also appear to covary with genetic endowment (see Loehlin et al., 1988, for a review). Perhaps the area that is getting the most current attention is personality. Dramatic reports of genetic influence in this domain are coming from the Minnesota Twins Project (e.g., Bouchard \& McGue, 1990; Tellegen et al., 1988), from developmental studies (e.g., Plomin \& Nesselrode, 1990), and from large-scale American (Loehlin, 1989), Soviet (e.g., Ravich-Scherbo, 1988), and Anglo studies (Eaves, Eysenck, \& Martin, 1989).

\section{Heritability of Attitudes}

According to McGuire (1969), "even theorists who agree on little else are in complete accord on the extreme and undemonstrated notion that all attitudes are developed through experience" (p. 161). Indeed, "Attitude theorists typically abhor hypothesizing genetic influence" (McGuire, 1985, p. 253). In a recent review of the attitude literature, Tesser and Shaffer (1990) reported no references to the heritability of attitude responses. In spite of the attitude of attitude researchers, there is evidence that at least some attitudes do have sizable heritabilities.

Altruism and aggression may be conceived of as broad social attitudes, and there is evidence of a genetic contribution (over $50 \%$ ) to individual differences on these dimensions (Rushton, Fulker, Neale, Nias, \& Eysenck, 1986). There is also evidence of a genetic component to job satisfaction (Arvey, Bouchard, Segal, \& Abraham, 1989) as well as to vocational attitudes (Keller, Bouchard, Arvey, Segal, \& Dawis, 1992; Scarr \& Weinberg, 1978). Using the Strong Vocational Interest Blank, Roberts and Johansson (1974) estimated a heritability of about .5 for various 
vocational types. Although Loehlin and Nichols (1976) found little evidence of a genetic component in attitudes toward God or organized religious activity in their high school sample of twins, Waller, Kojetin, Bouchard, Lykken, and Tellegen (1990) used a more complete assessment battery of religious attitudes; an older, more age-variable sample; and estimates of heritability from twins reared apart as well as together to estimate that about $50 \%$ of the variance in their instruments is genetically influenced.

Even more narrowly conceived attitudes seem to show some heritability. Thus, for example, Perry (1973) examined the heritability of attitudes toward alcohol, cigarettes, and coffee and found that attitudes toward drinking alcohol did have a genetic component $(51 \%)$, whereas attitudes toward drinking coffee and smoking cigarettes did not. More recently, Plomin, Corley, DeFries, and Fulker (1990) concluded from a parent offspring and sibling adoption design that television viewing time among 3-, 4-, and 5-year-olds has a significant genetic component (estimates vary by method and age).

Usually when one thinks of attitudes, the prototype that comes to mind is political attitudes of various sorts. Authoritarianism falls on the intersection of personality and ideology, and Scarr (1981) has provided evidence for the genetic transmission of authoritarianism. More recently, Martin et al. (1986) obtained responses from over 3,000 pairs of twins who filled out a 50-item conservatism scale (Feather, 1975; Wilson \& Patterson, 1968). This scale included items such as the death penalty, divorce, and jazz to which subjects responded "Yes," "?", or "No." Item-based estimates of additive genetic variance (based on the difference between monozygotic and dyzotic intraclass correlations and corrected for age) revealed 23 significant items. The range of heritabilities over the 50 items was from $8 \%$ to $51 \%$. (See Table 1 for a subset of items and their heritabilities.)

These same investigators (Martin et al., 1986) also reported on a sample of over 800 pairs of British twins who responded to a "Public Opinion Inventory comprising 40 frequently encountered statements relating to such issues as religion, sex, treatment of criminals, and nationalism [Eysenck, 1954]" (p. 4364). The items were aggregated into two composites, radicalism and toughmindedness. Each of the composites had large heritabilities (more than 50\%). In a more recent treatment (Eaves et al., 1989), heritability estimates for each of 60 items were presented. They ranged from $1 \%$ to $63 \%$. (See Table 2 for a subset of items and their heritabilities.)

In summary, although shared environments play a stronger role in the determination of attitudes than in the determination of personality, there appears to be a nontrivial genetic contribution to at least some attitudes.

\section{Gee-Whiz Response and the Application of Heritability to Psychological Theory}

The tradition in psychology is to assume that most interesting behavior is a product of the situation (or situational history) of the individual. Thus, when researchers learn that at titudes or complex behaviors such as altruism or viewing $T V$ are partially heritable, if researchers believe it at all, they are surprised, as in "Gee whiz, I didn't know that!" However, one rarely thinks through the implications for one's own research.

There are several reasons why researchers do not tend to make the connection between heritability and their own re-
Table 1

Selected Wilson-Patterson (W-P; 1968) Items: Their Heritabilities and Response Strength

\begin{tabular}{lcccc}
\hline \multicolumn{1}{c}{ W-P item } & $\mathrm{H}^{a}$ & $\begin{array}{c}\text { Median } \\
\text { response } \\
\text { time (s) } \\
\text { in Study 1 }\end{array}$ & $\begin{array}{c}\text { Mean } \\
\text { level of } \\
\text { influenceability } \\
\text { in Study 2 }\end{array}$ & $\begin{array}{c}\text { Net } \\
\text { social } \\
\text { influence } \\
\text { in Study 3 }\end{array}$ \\
\hline Death penalty & .51 & 3.84 & -.30 & .14 \\
Jazz & .45 & 3.79 & -.22 & -.04 \\
Royalty & .44 & 4.88 & .12 & -.30 \\
Apartheid & .43 & 3.90 & .06 & .25 \\
Censorship & .41 & 4.07 & .17 & .20 \\
White superiority & .40 & 4.18 & .24 & .79 \\
Divorce & .40 & 4.39 & .20 & -.00 \\
Military drill & .40 & 4.50 & $-\mathrm{c}$ & -.04 \\
Working mothers & .36 & 4.17 & $-{ }^{c}$ & -.00 \\
Self-denial & .28 & 5.98 & .27 & -.16 \\
Nudist camps & .28 & 4.28 & .04 & -.10 \\
Women judges & .27 & 3.74 & -.03 & .24 \\
Socialism & .26 & 5.05 & .34 & -.14 \\
Teenage drivers & .26 & 4.78 & -.01 & .02 \\
Learning Latin & .26 & 4.34 & .04 & -.44 \\
Bible truth & .25 & 4.40 & .27 & .10 \\
Divine law & .22 & 5.10 & .47 & -.11 \\
Floggingb & .21 & 4.39 & .35 & .10 \\
Straitjackets & .09 & 4.78 & .14 & -.20 \\
Coeducation & .07 & 4.17 & .25 & -.13 \\
\hline
\end{tabular}

Note. $\mathrm{H}=$ heritability estimate.

${ }^{a}$ Heritability estimates are from Martin et al., 1986. ${ }^{\mathrm{b}}$ The original item was caning. It was felt that flogging might be better understood by the U.S. subjects. ${ }^{\mathrm{c}}$ This item was not used in Study 2.

search. For some areas, the connection does not have to be made. In many individual difference areas, particularly in the area of intellectual abilities, the theoretical concerns deal directly with the heritability issue. A behavioral genetics analysis maps right onto the theoretical questions. For example, the estimate that so much of the variance in intellectual ability is due to shared environment and so much is due to genetics is as far as it needs to go. In this case, no other connection needs to be made.

When working with a specific response class, for example, altruism, the effects of heritability, with certain caveats, can safely be ignored. Suppose, for example, that subjects are randomly assigned to a similar or dissimilar "needy other" condition to test the hypothesis that similarity to a needy other increases altruism. If the heritability and the situational manipulation are additive in their effects on altruism, then heritability adds only individual differences "noise" to the experiment. The presence of heritability will make the experiment less powerful but not misleading, ' and the proportion of variance accounted for by the manipulations will be limited by the magnitude of the heritability coefficient. ${ }^{2}$

A third class of research concerns the testing of relatively general theories such as social learning theory (Bandura, 1985), dissonance theory (Festinger, 1957), or self-perception theory

\footnotetext{
${ }^{1}$ This assumes that the manipulation effects are additive to the determinants of heritability.

${ }^{2}$ This assumes that the manipulations or experimental treatments are typical of daily life. See the discussion in the Heritability section.
} 
Table 2

Selected Public Opinion Inventory (POI) Items: Their Heritabilities and Response Strength

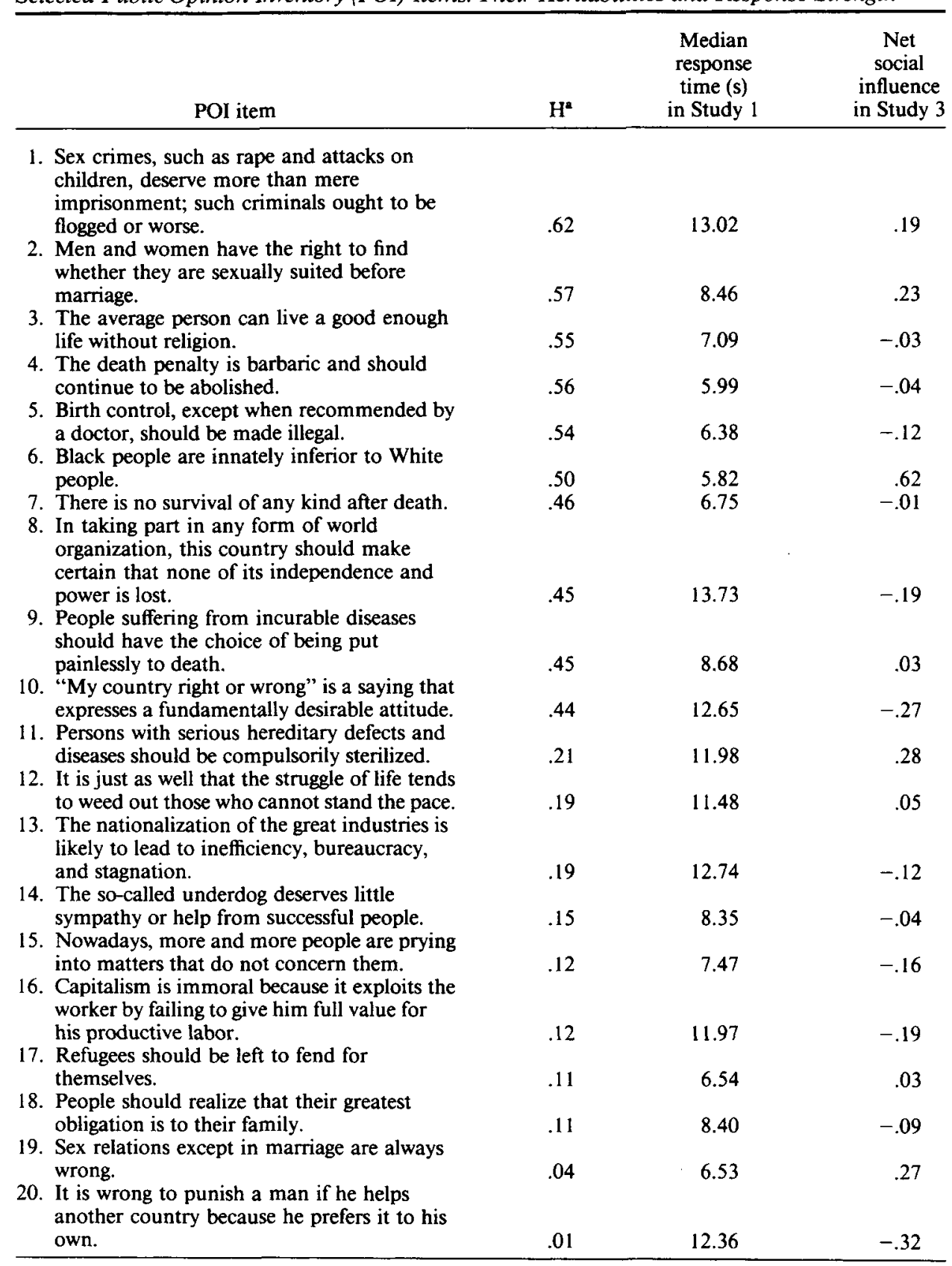

Note. $\mathrm{H}=$ heritability estimate.

${ }^{a}$ Heritability estimates are from Eaves, Eysenck, and Martin (1989, pp. 320-321).

(Bem, 1972). From the perspective of such general theories, it does not matter what the response is. It could be altruism, aggression, or the propensity to choose the color red. If one sees a model rewarded for doing it (the target behavior), engages in it for inadequate justification, or perceives oneself doing it, the probability of engaging in that behavior subsequently should increase. However, if there is variance in heritability across behaviors (which is known to be true) and heritability limits the effectiveness of a situational manipulation (a notion I discuss later), then the conclusions drawn on the basis of a single response or behavior will be misleading. That is, it does matter which response is being studied.

\section{Heritability}

Up to this point I have talked about heritability as if it were a fixed quantity indexing a kind of biological "fixedness." It is not. Heritability is the ratio of the phenotypic variance 
controlled by genetic variance to the total phenotypic variance which is controlled by genetic variance and environmental variance, for a particular population. Thus, it is not fixed, and it is determined as much by nurture as it is by nature. It can vary with the homogeneity or heterogeneity of the genetic makeup of the population-in a population of clones ( 0 genetic variance), any phenotypic variance at all would be environmental and heritability would be $0 \%$. It also covaries with the heterogeneity of environments--if everyone was confronted with exactly the same environment, then all the phenotypic variance would be due to genetic differences. If heritability was estimated on a random sample of the population and this sample had been subjected to a random sample of environments, then the estimate would give the typical percent variance due to genetic differences. To the extent that either persons or environments are not randomly sampled, estimates will change. In short, if one observes behavior in selected environments, all bets are off about the relative importance of differences in genes as typically estimated.

General theories such as dissonance theory or social learning theory specify selected conditions (aspects of environments) that control behavior. As such, reported estimates of heritability are not necessarily of concern. Estimates of typical heritability will not affect research outcomes if the experimental treatments (situations) are atypical of the normal variability across situations for the class of behaviors of interest, ${ }^{3}$ for example, attitudes. However, the treatments in most studies are, from both the theorist's and researcher's points of view, neither extreme nor exotic. Indeed, most of these theories count the ease with which they can be mapped onto everyday situations as a strength. Furthermore, experimenters often try hard to have their treatments look like something that an individual would encounter in everyday life, what Aronson and Carlsmith (1968) called mundane realism. To the extent that the treatments associated with a test of theory are typical of the environments encountered by subjects, then heritability estimates will limit conclusions (external validity; T. D. Cook \& Campbell, 1979): The greater the heritability of the response, the less impact any particular treatment will have on the response.

I have focused on the treatment, the situation, and the environment, but I could also focus on the other side of the same coin, the response. Responses with greater heritability are not less variable or predictable. Rather, comparatively more of their variance is associated with genetic differences than with situational differences. Therefore, in the usual experiment in which genetic differences are not assessed but situational differences are assessed, responses with greater heritability should appear stronger or less affected by the situation.

\section{Response-Strength Hypothesis}

Clearly, a number of suggestions about the behavior of responses with more or less heritability fall out of the definition of heritability. However, these suggestions can be taken further. On the basis of its definition, I have equated heritability with response strength in the sense that a strong response is less variable across situations. In this article, I go beyond that and hypothesize that heritability is associated with response strength in general. For example, there is nothing in the herita- bility formulation to predict what will happen to a response within a situation. Yet response strength often shows itself within situations. The purpose of the present article is to attempt to demonstrate this general heritability-responsestrength hypothesis empirically.

\section{Overview of the Present Studies}

I am not a behavioral geneticist nor do I have the resources to assess the heritability of a large number of responses. Fortunately, however, estimates for large sets of attitudes have been reported in the literature. Attitudes are convenient to work with because high and low heritability attitude items are measured the same way, thereby facilitating comparisons. I chose two sets of attitudes to provide an opportunity for replication across different items. The general hypothesis is that attitudes with greater heritability are stronger than attitudes with less heritability. Recent studies of attitudes suggested that stronger attitudes have greater accessibility as indexed by response speed. Study 1 measures the speed of attitudinal response as a function of attitude heritability. Study 2 tests an implication that falls out of the definition of attitude heritability; namely, that attitudes with greater heritability would be more resistant to a standard attitude change induction. In Study 3, attitude similarity and attitude heritability are varied and attraction to a stranger is measured. Attitude similarity is an important predictor of interpersonal attraction. If heritability is related to attitude strength, then the greater the attitude heritability, the stronger the similarity attraction relationship. Finally, Study 4 examines the relationships among the dependent variables used in the first three studies.

\section{Selection of Attitudes}

As already noted, I selected items for which heritability estimates based on large samples had already been reported in the literature. Two different sets were used for the purposes of replication. Both sets of items deal with conservatism, both sets are based on non-American, Anglo samples, and both sets have heritabilities estimates presented by Eaves et al. (1989) and Martin et al. (1986).

The first set of items comes from a 50-item version of the Wilson-Patterson conservatism scale (Feather, 1975; Wilson \& Patterson, 1968). Heritabilities were estimated on the basis of the responses of 3,810 (a $64 \%$ response rate) pairs of twins to a mailed questionnaire (Martin et al., 1986). The sample included 565 pairs of monozygotic (MZ) men, 1,232 pairs of $\mathrm{MZ}$ women, 351 pairs of dizygotic (DZ) men, 750 pairs of $D Z$ women, and 905 pairs of DZ mixed-gender siblings. (See the original sources for more details regarding the sample.) "Zygosity was determined by querying similarity in childhood and confusion of one twin for another by parents, friends and teachers, and [this technique] has been validated by blood typing [Martin \& Martin, 1975; Kasriel \& Eaves, 1976]" (Martin et

\footnotetext{
${ }^{3}$ I presume that only certain aspects of situations affect a particular response while other aspects may affect other responses. Therefore, when researchers talk about typicality of a situation, it is with respect to those aspects that are consequential for the behavior in question.
} 
al., 1986, p. 4364). Maximum likelihood estimates of polychoric correlations for the different twin types were computed. The estimate of additive genetic variance $(\mathrm{H})$ is a function of the difference between monozygotic and dyzotic intraclass correlations (corrected for age). I selected 20 items that (a) showed no significant gender differences and (b) spanned the range of heritabilities (see Table 1).

The second set of items comes from a public opinion inventory (POI) developed by Eysenck (1954). Heritabilities for each of the 60 items were estimated by Eaves et al. (1989) on a sample ple of 825 pairs (50\% response rate) of British twins who responded to a mailed sample. There were 120 pairs of $M Z$ men, 325 pairs of $\mathrm{MZ}$ women, 59 pairs of $\mathrm{DZ}$ men, 194 pairs of $\mathrm{DZ}$ women, and 127 pairs of DZ mixed-gender siblings. (See the original sources for more details regarding the sample.) Zygosity was determined as in the previous noted sample. Again, I selected 20 items that (a) showed no significant gender differences and (b) spanned the range of heritabilities (see Table 2).

\section{Study 1: Attitude Heritability and Response Latency}

An important research program concerned with response strength has been developed by Russell Fazio. His measure of response strength is the speed with which an individual reports his or her attitude toward some object. The construct validity for speed of response as an index of attitude strength is impressive. For example, the more often people express a particular attitude, the stronger that attitude should be. Powell and Fazio (1984) manipulated the number of times an attitude was expressed and measured speed of attitude response. As predicted, stronger (more frequently expressed) attitudes had faster responses. The stronger the attitude, the more likely it is to be activated automatically in the mere presence of the attitude object. Activated responses should facilitate consistent responding but interfere with inconsistent responding. Fazio, Sanbonmatsu, Powell, and Kardes (1986) first measured speed of response to various attitudes. They then showed subjects the name of attitude objects and had them respond to another stimulus. The presence of the name of the attitude object facilitated subsequent consistent responding and interfered with subsequent inconsistent responding only for attitudes with fast response times (strong attitudes) but not for attitudes with slow response times. There is also evidence that the faster a subject's attitude response time, the more likely it is that the subject will interpret an ambiguous situation as consistent with the attitude (Fazio \& Williams, 1986; Houston \& Fazio, 1989). Finally, the faster one's attitude response time, the more predictive of behavior is the attitude (Fazio, Powell, \& Williams, 1989; Fazio \& Williams, 1986).

In summary, attitude speed appears to be a valid index of attitude strength. If heritability of an attitude is associated with strength, then the greater the heritability of the attitude, the faster subjects should respond to it.

\section{Method}

Subjects. Twenty-three men and 37 women were recruited by means of advertisements in local papers and flyers posted around the campus of the University of Georgia. Each subject was paid $\$ 5$ for participating. A second sample of 33 men and 46 women participated in exchange for credit toward an introductory psychology course research requirement.

Procedure. Subjects were individually seated before a microcomputer and told that they would see a series of concepts to which they were to indicate their personal favorability on a 7-point scale $(1=$ very unfavorable and $7=$ very favorable). When they understood how to do this, the computer displayed each of the selected Wilson-Patterson (W-P; 1968) items (Table 1) one at a time (the order was independently randomized for each subject), and the subject recorded his or her level of favorability. The computer recorded the time it took for each attitudinal response. After another task, a similar procedure was undertaken with the POI items (see Table 2). On these items, subjects indicated their level of agreement or disagreement on a 7-point scale. The order in which subjects responded to the W-P and POI items was counterbalanced.

\section{Results and Discussion}

To get an idea of how fast subjects were responding to these items, I selected the median reaction time to each item within each set of attitudes. (I used medians because response times tend to be skewed.) On the average (the mean of these medians), it took subjects $4.44 \mathrm{~s}$ to respond to each W-P item and $9.32 \mathrm{~s}$ to respond to each POI item. Given the difference in length of the average item within each set, this difference is not surprising.

Subject as the unit. The first analysis used the subject as the unit. In theory, the test is straightforward: The correlation of each subject's response latency to an item with the heritability of that item should be negative. However, there is a potential artifact. Response time is partially controlled by reading time. Subjects respond slower to longer items than to shorter items. Therefore, any association of length with heritability could be problematic. (The correlation between heritability and the number of letters in each item is -.165 for the W-P items and .12 for the POI items.) To deal with this problem, the number of letters in each item were counted and the partial correlation between response time and heritability was computed with item length held constant for each subject. ${ }^{4}$ The mean withinsubject partial correlation is small in magnitude but signifcantly different from zero ${ }^{5}$ for each item set, mean $r=-.06$, $t(138)=-2.97, p<.01$, for the POI items; mean $r=-.15$, $t(138)=-7.32, p<.001$, for the W-P items.

Item as the unit. Another way of approaching the hypothesis is to treat the attitude item as the unit of analysis instead of the subject. In this case, the median response time (across subjects) was calculated for each item. Because there were only 20 items in each set, to gain power I decided to test the hypothesis across sets ( $n=40$ items). Before pooling the items, both heritability and median response times (corrected for item length) were

\footnotetext{
${ }^{4}$ Because of the way in which sample correlations are distributed around their own mean, it is best to transform them by means of Fisher's $z$ before using them as data points in the computation of other parametric statistics. I use correlations and partial correlations as data points in a number of statistical operations in this article. In each case, the correlation has been converted to Fisher's $z$ for computation and converted back to a correlation when reported in text and tables.

${ }^{5}$ Two-tailed tests of significance are reported throughout, even where the direction of a relationship is predicted a priori.
} 
standardized within each set. The correlation between these variables was then computed across all 40 items from both item sets. The resulting correlation $(r=-.36, p<.02)$ is significant.

Previous research has found that speed of response is a reliable and valid indicator of attitude strength. Although the within-subject correlations are small, there appears to be an association between speed of attitude response and the estimated heritability of the item. There are, however, some differences between Study 1 and other studies intended to measure reaction time. In Study 1, subjects were not instructed to respond as fast as they could. It was assumed that they responded as soon as their attitude was accessed and that deviations from this strategy were uniformly distributed across items.

It is also worth noting that item length was not experimentally controlled in this study. I addressed this problem through statistical control. Even with this control, there were detectable effects of heritability. (Indeed, the uncorrected correlations were similar in magnitude to the partial correlations, and partialing made little difference one way or the other.) In summary, I conclude that speed of response is associated with attitude heritability.

\section{Study 2: Attitude Heritability and Conformity}

The ease with which a response can be changed should also be related to heritability. One of the central areas of attitude research throughout its modern history is conformity. Some exquisite pioneering work was done by Muzafer Sherif (1937), who showed that in the absence of any objective referent, people will adopt the judgments of those around them. They appeared to do so without being aware that they were being influenced, and they continued to use the adopted judgments even in the absence of continued social influence (but see Jacobs \& Campbell, 1961). At the opposite end of the continuum, Solomon Asch (1956) attempted to show that when making judgments about stimuli that were unambiguous, people would show their independence. He used stimuli that were so clear that judgments in the absence of social influence were virtually error free. To his surprise, however, rather than independence, he found conformity to the incorrect judgments of others on about one-third of the judgments.

Subsequent work has shown that conformity forces play an important role in both destructive and constructive social processes. In one of social psychology's most dramatic demonstrations, Stanley Milgram (1965) showed that about two-thirds of his sample, as a result of conformity pressures, would continue to give increasingly more intense electric shock to another person who is screaming in pain. (It can be inferred that these subjects know that this behavior is morally wrong because other subjects drawn from the same population judge this behavior to be clearly wrong and claim that they would not engage in it.) Latané and Darley (1970) showed that bystander intervention in an emergency is also affected by conformity forces. The presence of others inhibits intervention, in part because the inaction of the others leads persons to interpret the situation as benign.

In summary, conformity is a pervasive force in social life. It affects judgments of the ambiguous and of the clear; it plays an important role in the harming and helping of others. Is its im- pact moderated by the heritability of the attitude in question? Conformity directly addresses the question of malleability of behavior across situations. It is an index of the extent to which behavior changes with changing situational norms. Attitudes with higher heritabilities are (relatively) less situationally malleable. Therefore, I expect that attitudes with higher heritabilities will be stronger, that is, will show less change, as a result of shifting norms.

\section{Method}

Overview. This study was run using only W-P items. In the first phase, agreement norms for items were obtained. In the second phase, new subjects were provided norms for each item and asked to indicate their level of agreement with the item. To detect the effect of shifting norms, the norms were systematically varied above and below those obtained in the first phase.

Subjects. Subjects were recruited from an introductory psychology course at the University of Georgia and received course credit as an incentive. Thirty-one men and 32 women served in Phase 1, whereas 56 men and 81 women served in Phase 2.

Phase 1. Subjects were run in small groups. They received a questionnaire containing 18 of the selected W-P items and were asked to record their attitude by indicating the extent of their agreement on a 5-point graphic scale with the points labeled strongly oppose, oppose, neutral, favor, or strongly favor for each item.

Phase 2. The percentage of Phase 1 subjects who favored or strongly favored and the percentage of subjects who opposed or strongly opposed each item was computed. These norms were used to construct two versions of a second questionnaire. In Version 1, some of the items were paired with false norms that were $15 \%$ more favorable than the Phase 1 norm, and the remaining items were paired with norms that were $15 \%$ less favorable. ${ }^{6}$ Version 2 was the mirror image of Version 1: The items that had false favorable norms on Version 1 had false unfavorable norms on Version 2; the items that had false unfavorable norms on Version 1 had false favorable norms on Version 2.

Phase 2 subjects were given either Version 1 or Version 2 of the questionnaire. They read that they were to indicate their attitudes and that "Since many people are interested in how their peers feel on a given issue we have provided you with information on the responses of other UGA [University of Georgia] students for these items." Each item had associated with it the false norm and a 5-point graphic scale.

\section{Results and Discussion}

Subject as the unit. The 7 lowest heritability items were classified as low heritability, and the 11 highest heritability items were classified as high heritability (see Table 1). Favorability of responses to each item were standardized over subjects and versions of the questionnaire. Using these standard scores, four mean responses for each subject were calculated: favorable norm, high heritability items; unfavorable norm, high heritability items; favorable norm, low heritability items; and unfavorable norm, low heritability items. These within-subject means were subjected to a 2 (gender) $\times 2$ (influence: favorable vs. unfavorable) $\times 2$ (heritability) analysis of variance (ANOVA), with the last two variables treated as repeated measures. Overall,

\footnotetext{
${ }^{6}$ The phrasing of this normative feedback differed over items. For some items, the feedback was phrased in terms of the percentage of people who favored the item, for other items it was phrased in terms of the percentage of people who opposed the item.
} 
men tended to be less favorable to the issues $(M=-.01)$ than were women, $M=.04, F(1,132)=5.00, p<.03$, and the influence of the norms was effective, $F(1,132)=5.97, p<.02$; moreover, as predicted by the hypothesis, the difference between favorable norms and unfavorable norms is smaller for the high heritability items $(M=.02$ vs. $M=-.03)$ than for the low heritability items $(M=.06$ vs. $M=-.10)$. The crucial interaction, however, did not approach significance $(F=1.14)$.

To get greater separation between the high and low heritability items, the data were reanalyzed with the four highest heritability items (death penalty, apartheid, royalty, and jazz) and the four lowest heritability items (divine law, coeducation, flogging, and straitjackets). This analysis yielded clear results.

Again, women were more favorable to the items than men, $F(1,132)=8.72, p<.01$. The influence main effect was still present, $F(1,135)=4.40, p<.04$. Again, the crucial Heritability $X$ Influence interaction was present, but this time it was significant, $F(1,135)=5.23, p<.01$. As can be seen in Figure 1 , norms make a clear difference with the low heritability items, whereas the effect of norms is trivial for the high heritability items. When looking at the extremes, it appears that conformity pressures operate more strongly for low heritability than for high heritability attitudes.

Item-level analyses. The hypothesis that high heritability attitudes are less influenceable was examined using the item as the unit of analysis. This analysis was relatively straightforward. For each item, the mean response given to the favorable norm and the mean response given to the unfavorable norm were separately calculated. The difference between these two means serves as an index of the extent to which norms have an impact on the reported attitudes: Positive numbers indicate positive influence; negative numbers indicate negative influence or a "boomerang effect." This influenceability index was then correlated with heritability across the items.

This bivariate distribution is shown in Figure 2. The correlation between heritability and influenceability is $-.51(p<.03)$. At the item level, there is a clear association between heritability and influenceability. Low heritability items are more influenced by the norms than high heritability items. Indeed, there appears to be a boomerang effect on attitudes with the greatest heritabilities.

The data from this study seem to support the hypothesis that lower heritability attitudes are more easily influenced by norms and hence, are less strong than higher heritability attitudes. The hypothesis for this study comes closest to following directly from the definition of heritability. Differences in norms are a very nice proxy for the kinds of environmental differences that might effect phenotypical attitudes. High heritability estimates indicate a small environmental influence relative to the genetic influence on the attitude.

In spite of the straightforward nature of the derivation of the hy pothesis and the strength of the item-level results, I still urge caution. This study was run using only one set of items. ${ }^{7}$ Furthermore, the individual-level results were significant only on the most extreme items.

\section{Study 3: Attitude Heritability and Social Functioning}

Do attitudes with greater heritability play a more important role in social life than do attitudes with lower heritability? Atti-

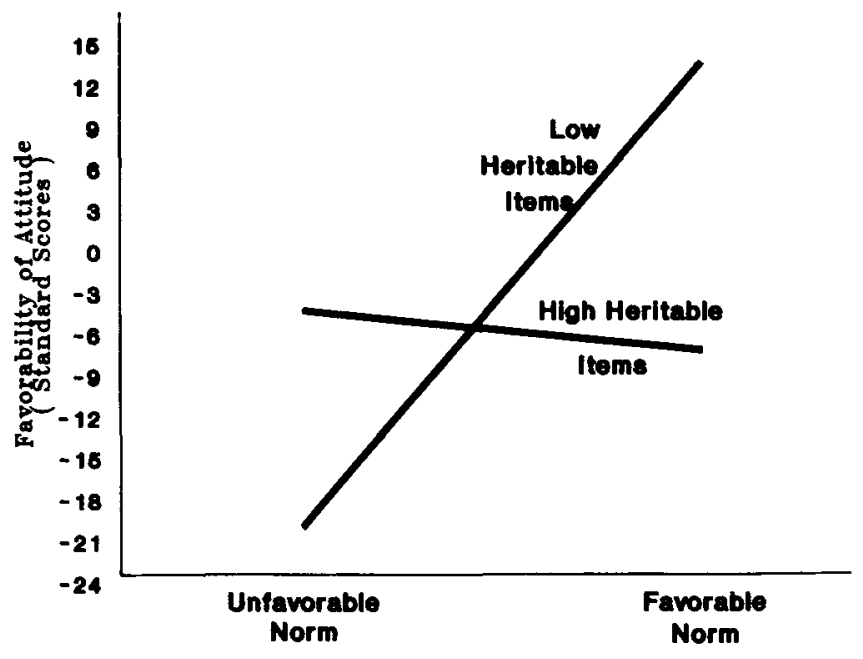

Figure 1. Study 2. Favorability of attitudes as a function of heritability (4 highest vs. 4 lowest heritable items) and favorability of norm.

tudes serve a variety of functions in everyday life (e.g., Katz, 1960; Pratkanis, Breckler, \& Greenwald, 1989; Smith, Bruner, \& White, 1956). For example, ego-defensive attitudes help a person defend against unwanted thoughts and beliefs about the self. Instrumental attitudes help a person to fit into groups and social settings and to mediate rewards. Value-expressive attitudes give a person a sense of who he or she is. Attitudes that serve a knowledge function help a person to interpret what might otherwise be an ambiguous situation.

Each of these functions can play themselves out in individual or social situations. Regardless of the function served, one might expect that people would be attracted to others who hold similar attitudes. Others who support one's ego-defensive attitudes would not be threatening. Similar others are likely to validate one's interpretation of the situation, confirm one's selfview, and provide easy or uncostly interaction. Thus, regardless of the attitude function, the prediction is that an individual is attracted to others who hold similar attitudes.

Literally hundreds of studies attest to the generality and power of this prediction (Byrne, 1971). In one of the earliest and best known studies, Theodore Newcomb (1961) found that he could predict who would come to like whom in a college dormitory before any of the interactants ever met simply by knowing the degree of similarity in their attitudes. In a paradigmatic series of studies, Donn Byrne (1971) and his colleagues have formulated what they call the law of attraction: The greater the percentage of similar attitudes, the more attracted one is to another.

An aspect of attitude strength is how consequential the atti-

\footnotetext{
${ }^{7}$ I recently attempted a conceptual replication of this study using the POI items. The influence manipulation had a very strong effect, about .4 of a standard deviation, but there was not a hint of an Influence $\times$ Heritability interaction. Although there were a variety of differences between this attempted replication and the original study, I suspect that the strength of the manipulation wiped out the more subtle heritability effects.
} 


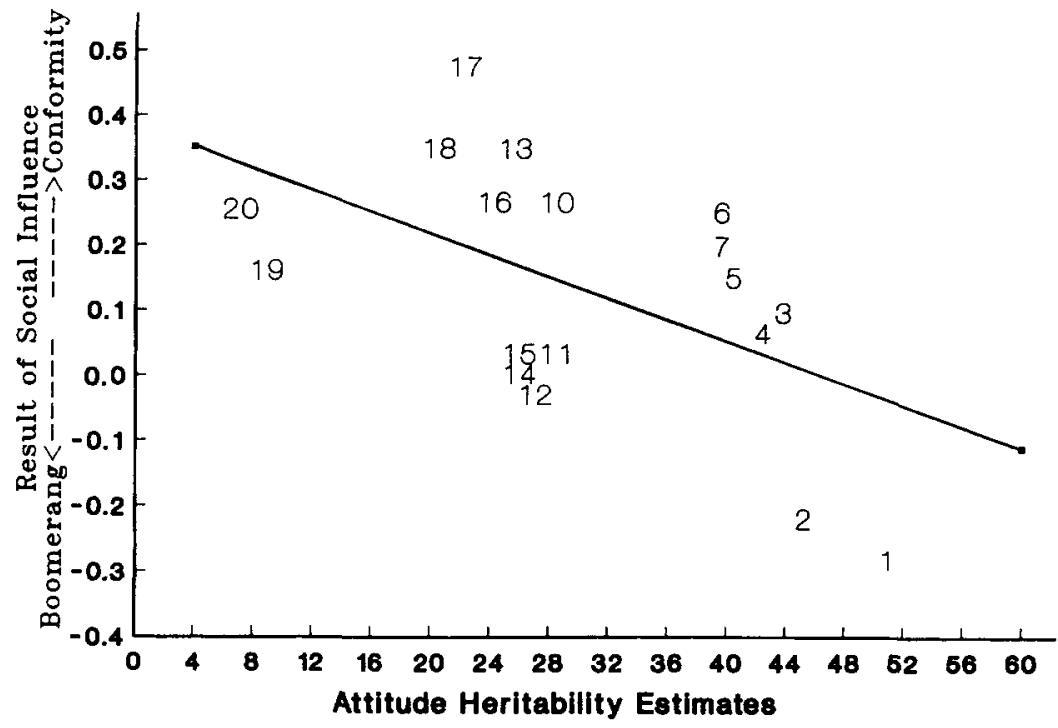

Figure 2. Study 2. Bivariate distribution of heritability and net influence on the selected Wilson-Patterson items. (Numbers refer to specific items listed in Table 1.)

tude is in social life. In particular, the hypothesis tested in Study 3 is that the greater the attitude heritability, the stronger the relationship between attitude similarity and attraction.

\section{Method}

Overview. Subjects viewed five attitudes of a number of opposite-sex strangers. The proportion of similar and dissimilar attitudes and the heritability of the attitudes were varied across the strangers. Subjects scaled how much they would be attracted to the stranger.

Subjects. The subjects were the first sample from Study 1. Thirtyseven women and 23 men were paid $\$ 5$ and were recruited through advertisements in the local papers and flyers by the University of Georgia's Survey Research Center.

Procedure. Each subject was individually seated before a microcomputer. First, subjects entered their response to each of the W-P items on a 5-point graphic scale ranging from strongly favor to strongly oppose. Then they were confronted, one at a time, with the description of 24 opposite-sex strangers. For each stranger, they indicated how much they would like this person as a friend, as a romantic partner, and as a spouse. Each attraction item was answered on a 7-point graphic scale that ranged from dislike very much (1) to like very much (7). Following this, subjects went through exactly the same procedure for the POI items. Order was counterbalanced. Half the subjects went through the procedure for the W-P items first; half the subject went through the procedure with the POI items first.

Construction of the strangers. Within each set of items, W-P or POI, 24 strangers were constructed. Each stranger was associated with a different set of five attitudes. Construction was based on trial blocks of 6 strangers. (Trial blocks were transparent to the subjects.) Within each trial block, 1 stranger agreed with the subject on 0 items, another on 1 item, another on 2 items, and so on through 5 items. Level of agreement was randomly ordered within block. Agreement was defined as the same response to the item as the subject's; disagreement was defined as a displacement of the subject's response by 2 units (either more favorable or less favorable) on the 5-point scale. Agreement or disagreement was randomly assigned to attitude items within each stranger. Figure 3 illustrates a typical computer screen depicting a stranger and the subject's attraction responses to that stranger on items from the W-P set.

There were four trial blocks within each attitude set. Each of the 20 attitude items appeared six times across the 24 strangers. Attitudes were counterbalanced across levels of agreement: Each item appeared once in a 0 -agreement set, once in a 1 -agreement set, and so on through the 5-agreement set.

\section{Results}

The heritability hypothesis is based on the notion that attraction is related to attitude similarity. To test this assumption, attraction to a stranger was correlated with attitude similarity over the 24 stimulus strangers (within each attitude set). Three such correlations were computed for each subject: attraction as a friend, as a romantic partner, and as a spouse. Each of these correlations were transformed by means of Fisher's $z$ and were subjected to a 2 (gender) $\times 3$ (attraction type: friend vs. partner vs. spouse) ANOVA with the last factor considered as a repeated measure.

The assumption of attitude similarity and attraction is well supported. With the W-P items, the mean within-subject correlation (converted back from Fisher's $z$ ) between attitude similarity and attraction is a substantial .69. None of the ANOVA effects were significant (all $F_{\mathrm{S}}<1$ ). Using the POI items, the mean correlation was higher for women, .72, than for men, .55, $F(1$, $58)=13.60, p<.01$, but again both were quite respectable. Neither attraction type nor its interaction with gender were significant $(F<1)$.

Subject as the unit. Testing the heritability hypothesis is more complicated. What is needed is an index of the extent to which each item is influential in affecting the similarity attraction relationship. To compute such an index, the attraction ratings were regressed on the level of similarity across the 24 strangers within each attitude set for each subject. If a particular 


\begin{tabular}{lc} 
Other's Response & \multicolumn{1}{c}{ Topic } \\
STFONGLY FAVOR & Teen-age drivers \\
NEUTRAL & Foyalty \\
NEUTRAL & Self-denial \\
OFFOSE & Flogging \\
FAVOF: & Eible truth
\end{tabular}

How much would you 1ike this person as a FRIEND? 5
as a ROMANTIC PARTNER? 5
as a SPOUSE? 4

Figure 3. Study 3. Example of the computer screen format showing the attitude similarity manipulation and the prompt for attraction response.

stranger has an attitude item(s) that is quite strong, then similar feedback on that item should cause the stranger to be more attractive than predicted by the regression line; dissimilar feedback should cause the stranger to be less attractive than predicted by the regression line. If the stranger has no particularly strong or weak items, then the stranger's attraction level should be close to the regression line. If the stranger has a particularly weak attitude item(s), then the stranger's attraction level should be closer to the mean than to the regression line.

Following up on this logic, the attraction residual was calculated for each stranger. Two registers were defined for each attitude item: a similar feedback register and a dissimilar feedback register. For each stranger, the residual was averaged into the appropriate register (similar or dissimilar feedback) for each attitude item associated with the stranger. Recall that each item was associated with 6 different strangers. By averaging the residuals in the similar and dissimilar registers over these strangers for an item, an index was derived of the extent to which feedback on this item was consequential, that is, the extent to which strangers were liked more than was predicted from the regression line when the item feedback was similar and the extent to which strangers associated with this item were disliked more than predicted from the regression line when the item feedback was dissimilar. These indexes were computed for each type of attraction: friend, romantic partner, and spouse. Because preliminary analyses revealed no differences over these types, they were pooled to simplify presentation of the results.

These operations provide the information necessary to test the heritability hypothesis. If heritability is associated with attitude strength, then the greater the heritability, the more similar feedback should cause the stranger to be liked and the more dissimilar feedback should cause the stranger to be disliked. In summary, because heritability should be positively correlated with the similarity index and negatively correlated with the dissimilarity index, there should be a significant difference between these two correlations.

Each of these correlations, that is, between heritability and the similarity index and heritability and the dissimilarity index, was computed for each subject and converted to Fisher's $z$. These transformed correlations were then subjected to a 2 (gender) $\times 2$ (index: similar vs. dissimilar) ANOVA with repeated measures on the last factor.

Although the mean correlations were low, the hypothesis receives support. Focusing first on the W-P items, the mean correlation between heritability and the residual is positive when the feedback is similar (mean $r=.06$ ); negative when the feedback is dissimilar (mean $r=-.06$ ); and the difference between these two mean correlations is significant, $F(1,58)=$ $6.58, p<.01$. The same affects are present for the POI items although slightly less pronounced. The mean correlations for similar and dissimilar feedback were $r=.06$ and $r=-.04$, respectively, $F(1,58)=4.79, p<.05$. No other effects were significant within the analysis for either item set. (All ps $>.20$.)

By subtracting the mean item-attraction residual given negative feedback from the mean item-attraction residual given positive feedback, an index of net social influence is created: Positive numbers indicate more influential attitudes and negative numbers indicate less influential attitudes. This index was computed for each item for each subject within each attitude set. The average within-subject correlation between heritability and net social influence, although small, was in the appropriate direction: mean $r=.08, t(59)=2.48, p<.02$, for the W-P set; mean $r=.06, t(59)=1.92, p<.06$, for the POI set.

Item as unit of analysis. To use the item as the unit, the mean similar feedback register (overall subjects) and the mean dissimilar feedback register was computed for each item. Because there were only 20 items within each set, the variables were 
standardized within each attitude set and the sets were combined $(N=40)$ to provide a more powerful test. The results were as predicted. Given similar feedback, the correlation between mean attraction residual and heritability was . 31 ; given dissimilar feedback, the correlation was - .22; and the difference between the two correlations was significant, $t(37)=2.01, p=.05$.

It is also possible to compute a net social influence index on the item level. For each item, the mean item-attraction residual given negative feedback was subtracted from the mean item-attraction residual given positive feedback. After standardizing heritability and the social influence index within attitude sets, the correlation between these variables was computed over the combined items $(N=40)$. As predicted, the correlation between heritability and net social influence was positive $(r=.29$, $p<.07$ ).

\section{Discussion}

Although the effect sizes are not large, there seems to be some support for the idea that attitude strength as reflected in the attitude similarity attraction relationship is related to attitude heritability. On the one hand, note that this hypothesis is not easily derivable from the definition of heritability. There is nothing in the definition of heritability that suggests that persons should be attracted to others with the same phenotype or even to situations that would support the same phenotype.

On the other hand, sociobiologists do argue for assortative mating. Rushton's (1989) notion of "genetic similarity" proposes that "genetically similar people tend to seek one another out and to provide mutually supportive environments such as marriage, friendship and social groups" (p. 503). In his review of the literature, Rushton provided comparative evidence across part of the phylogenetic scale (including humans) of genetic similarity detection and attraction. For example, Russell, Wells, and Rushton (1985) found a correlation of .36 for independent estimates of heritability and assortative mating on 36 anthropometric measurements. Perhaps more to the point, Rushton (1989) also reported a correlation of .40 between itemlevel similarity in friendship pairs and heritability estimates across 40 of the W-P items. The experimental results from Study 3 nicely complement Rushton's correlational study.

There is one aspect of the sociobiological argument that was not supported in these data. Recall that subjects made attraction ratings to the stranger as a friend, as a dating partner, and as a spouse. From a sociobiological point of view, one might have expected greater assortative pressure with respect to spouse than to friend. There were no differences in the similarity attraction relationship by role, for example, friend versus spouse. Perhaps this was too subtle a prediction to make given the present restricted experimental situation, but that expectation was not realized.

In introducing this study, I reviewed a variety of psychological attitude functions and argued that regardless of the function, one should be more attracted to a similar other than to a dissimilar other. Furthermore, the stronger the attitude, the stronger the similarity attraction relationship. From this I successfully predicted that greater heritability of an attitude would intensify the attraction similarity relationship. Regardless of whether these results are framed in terms of sociobiology or the social psychology of attitudes, attitudes with greater heritabilities appear to be socially more consequential than attitudes with lower heritabilities.

\section{Study 4: Putting it Together}

Tables 1 and 2 list the attitude items I used in each of the sets along with their heritabilities and the summary item-level statistic from each of the studies. It has been seen how each of the summary statistics relates to heritability. Now their relationships to one another can be examined. There is nothing in the previous work to guarantee their intercorrelations. However, if they function in a similar way or if they are alternative measures of the same construct, for example, strength, then a single factor should account for their covariation.

Table 3 contains the correlations among attitude heritability, attitude accessibility as measured by response time ${ }^{8}$ (Study 1), the extent to which each of the W-P items were influenced by the norm manipulation (Study 2), and the extent to which each of the items influenced the similarity attraction to a stranger relationship (Study 3, net social influence).

Focus first on the W-P items. All of the variables, as noted before, are at least moderately related to heritability. Table 3 reveals that they are all also related to accessibility. Surprisingly, the relationship between influenceability and social influence is close to zero.

The correlations were subjected to a principal components analysis. A single factor produced an eigenvalue greater than one. That factor accounted for $54 \%$ of the variance in the matrix. The factor pattern is shown in the last column of Table 3 and the communalities are shown on the main diagonal. The principal components analysis leads to several conclusions.

First, there is only one commonality among these variables. Second, that commonality accounts for a substantial portion of the variance and, hence, is important. Moreover, in spite of attitude heritability being the only variable not measured in the laboratory, it is an important part of what these variables have in common. What is this common thing? Perhaps it is attitude strength, but I have more to say about this in the General Discussion section.

The third conclusion is that in spite of the importance of what these variables have in common, almost half the variance is unaccounted for. Ordinarily, accounting for more than half of the variance would be quite sufficient. After all, the variance unaccounted for usually contains substantial errors of measurement. In this case, however, the raw data are highly reliable. (Recall that each datum entering into these correlations is a mean aggregated over a number of subjects and over a number of observations within subjects.) Thus, these variables have a substantial amount of variance that is independent of heritability and the other variables in the set. Earlier I noted that the correlation between influenceability and social influence was quite low. Although both variables correlate substantially with the common factor, social influence has a relatively lower factor

\footnotetext{
${ }^{8}$ Actually, the entries for response time are the partial correlations between response time and each of the other variables with the effect of number of letters partialed out. See Study 1 for the reason.
} 
Table 3

Correlations Among Variables Across Studies

\begin{tabular}{|c|c|c|c|c|c|}
\hline Variable & 1 & 2 & 3 & 4 & $\begin{array}{l}\text { Factor } \\
\text { pattern }\end{array}$ \\
\hline \multicolumn{6}{|c|}{ Wilson-Patterson items } \\
\hline $\begin{array}{l}\text { 1. Heritability } \\
\text { 2. Response time } \mathrm{e}^{\mathrm{a}} \\
\text { 3. Influenceability } \\
\text { 4. Social influence }\end{array}$ & .56 & $\begin{array}{r}-.34 \\
.68\end{array}$ & $\begin{array}{r}-.51 \\
.57 \\
.57\end{array}$ & $\begin{array}{r}.34 \\
-.46 \\
-.03 \\
.33\end{array}$ & $\begin{array}{r}.75 \\
-.83 \\
-.76 \\
.57\end{array}$ \\
\hline \multicolumn{6}{|c|}{ POI items } \\
\hline $\begin{array}{l}\text { 1. Heritability } \\
\text { 2. Response time }{ }^{\mathrm{a}} \\
\text { 3. Influenceability } \\
\text { 4. Social influence }\end{array}$ & .69 & $\begin{array}{r}-.46 \\
.61\end{array}$ & $\bar{z}$ & $\begin{array}{r}.25 \\
-.18 \\
-.30\end{array}$ & $\begin{array}{r}.83 \\
-.78 \\
-.55\end{array}$ \\
\hline
\end{tabular}

Note. Communalities are on the diagonal. $\mathrm{POI}=$ public opinion inventory.

${ }^{a}$ Correlations with response time are partial correlations with the number of letters in the item partialed out. See Study 1. ' Correlations are based on 18 items.

correlation and communality suggesting that it, rather than influenceability, is the more unique entry. Indeed, social influence is the only variable dealing specifically with interpersonal issues.

The first factor accounted for $53 \%$ of the variance among the POI items. Although there is no measure of influenceability, the conclusions to be drawn for these items are very much the same as those outlined earlier.

\section{General Discussion}

By and large, the data reported here are consistent with the idea that high heritability attitudes are stronger than low heritability attitudes. That is, more heritable attitudes are responded to more quickly, they are more difficult to change, and are more consequential in attraction. Before discussing the notion of attitude strength and how the present approach might fit into general theory testing, there are three issues that must be dealt with: the small effect size, the correlational nature of heritability, and the potential mediators of attitude heritability.

\section{Small Effects}

In general, the reported effect sizes, particularly when the subject is the unit, are quite small. Small effects are not difficult to understand. The responses are measured with some error and are multiply determined, that is, the variables that were manipulated or measured in each study are undoubtedly only a small subset of variables that help determine the response.

Moreover, and perhaps most important, the heritability estimates were not taken on the population that participated in these studies. Estimates for the W-P items were based on an Australian sample and estimates for the POI items were based on an English sample. Any differences in the meaning of the items, the culture, or the gene pool between the present sample and the sample on which the heritability estimate was derived will attenuate the influence of heritability. In view of errors inherent in estimating heritability, the differences in samples, and the errors in measuring the response, it is remarkable that anything could be detected! Nevertheless, the small effect sizes obviously limit the accuracy of prediction that might be made for any particular subject or item.

\section{Correlational Nature of the Studies}

It is known from the present set of studies that heritability is correlated with response speed, resistance to persuasion, and the similarity attraction relation. Because of the correlational nature of the relationship, two questions can be raised. The first question concerns causal ordering, that is, is heritability the antecedent or the consequence? From a logical point of view, it is difficult to see how any of the responses measured here might have caused heritability. Perhaps a case could be made for response speed because it might be thought of as having a physiological basis and as such being correlated with one's genetic endowment. However, this argument will not work because it relies on general individual differences, that is, some individuals are wired to be faster than others. The data I present here come from within-subject comparisons.

The second question concerns spuriousness. Is there a third variable(s) causing both heritability and response? Because heritability is not manipulated, it is undoubtedly correlated with a host of other variables. However, it is difficult to imagine a third variable that would unambiguously fill the bill. Suppose, for example, that attitude importance (or emotionality or extremity) was correlated with both heritability and resistance to persuasion. Suppose further that the correlation between heritability and resistance goes to zero when importance is partialed out. This would certainly be consistent with the hypothesis that the relationship between heritability and resistance is spurious. However, as Simon (1954) has so eloquently pointed out, such a pattern of correlations would also be consistent with the hypothesis that heritability caused importance, which caused resistance. There is no a priori way of deciding which is correct.

Under most circumstances, heritability, as a variable tied up with the biological endowment of the organism, would be given causal priority. However, discussions with colleagues reveals a reluctance to do so in this case. Perhaps such reluctance flows from an unwillingness to believe that attitudes can have a genetic basis.

\section{Genetic Basis of Attitudes}

Is there a gene for attitudes toward jazz in the same way as there is a gene for eye color? I doubt it. However, one can imagine a number of mechanisms by which more directly heritable physical differences might play themselves out in specific attitudes in a particular cultural milieu. The following paragraphs contain some examples.

Sensory structures. Genetic differences in sensory structures such as taste, hearing, and sensitivity to touch could affect attitudes toward food, loud music, preferences for lovemaking practices, and so forth. Genetically derived color blindness rules out preferences between undetectable color differences.

Body chemistry. It is known that various body chemicals, for example, hormones, have profound effects on behavior. It is 
difficult to believe that there are not differential genetic effects in their various balances. Indeed, Dabbs (1989) has found a correlation between individual differences in testosterone and occupation that he suggested could be due to interests; Schachter, Kozlowski, and Silverstein (1977) have argued for individual differences in body chemistry and attitudes toward cigarettes as expressed in smoking behavior. The link between genetic differences in body chemistry and the desire for alcohol is frequently discussed even in the popular media (Flaste, 1991).

Intelligence. To the extent that intelligence has a nonzero heritability and social attitudes represent the product of the kind of cognitive reasoning involved in intelligence tests, those attitudes will have a heritable component. Indeed, Scarr (1981), in a study of adoptive and biological families, found that "differences in sociopolitical attitudes, measured by the F-scale, appear to be genetically transmitted from parents to their children in the form of verbal ability" (p. 399).

Temperament and activity level. Genetic differences in activity level (e.g., Kohnstamm, Bates, \& Rothbart, 1989) could easily be imagined to have an impact on attitudes toward various free-time pursuits and career options.

Conditionability. Eysenck (1954) has developed a highly creative argument about how genetic differences in conditionability might play themselves out in certain social-political attitudes. To simplify, children are punished for transgressions. Individuals who condition easily will learn to experience fear in anticipation of a transgression. The fear will prevent them from engaging in the transgression. Such individuals are likely to hold attitudes that society condones. Individuals who do not condition as readily are more likely to hold more tough-minded attitudes.

C. G. Jung (1939) has suggested that there may be hard-wired symbols (archetypes) that inhere in a shared racial unconscious. Indeed, there are probably more snake phobics among us than automobile phobics in spite of the fact that more people are killed by automobiles than snakes. (See M. Cook \& Mineka, 1990 , for work showing a built-in propensity for fear of snakes among rhesus monkeys.) My own position is not that extreme. For the time being, I think that a plausible case can be made for attitude heritability using more well-accepted mechanisms like those sketched out earlier. Furthermore, it seems reasonable to assume that different heritable attitudes may be supported by different biological cultural interactions.

\section{Niche Construction or Attitude Strength}

The empirical work reported here addresses the question of whether attitude strength is associated with attitude heritability. The answer appears to be yes. As noted in the introduction of this article, however, there is a sense in which the question and answer are part of a tautology. One definition of strength is that the response does not change from situation to situation. For a response to be high in heritability means that relative to its total variation, it shows less situational (or environmental) variation than a response that is low in heritability. However, it does not necessarily follow from that observation that responses with greater heritabilities will be made with greater speed or will be more reinforcing or more consequential in interpersonal attraction than responses with lower heritabilities.

If there is no logical necessity for it, why do these various indexes of attitude strength show an association with heritability? The original hypothesis was derived from the intuitive notion that attitudes that show one kind of strength will be strong in other ways as well. The intuitive answer will not work either. In spite of the single dimension to emerge in the principal components analysis (Study 4), attitude strength is not necessarily a unitary dimension. For example, Abelson (1988) has factor analyzed various indexes of the conviction with which people hold various attitudes and found several dimensions in that domain of attitude strength alone. (See also Petty \& Krosnick, in press, for a series of state-of-the-art discussions of attitude strength.)

The account that I find plausible is as follows: Attitudes that are high in heritability have a more or less direct biological substrate that is enduring. Because the substrate is enduring, attitude change is resisted and uncomfortable. Therefore, psychological protection mechanisms develop around these attitudes. The attitudes become more accessible, that is, response speed is increased. Accessibility is a kind of vigilance. An attitude that is quickly brought to the fore is functional. Accessible attitudes help one to interpret situations and behave in ways that are congenial with the attitude (Fazio \& Williams, 1986). Such interpretations and behavior shield the attitude from jeopardy. The attitudes of people around oneself have profound effects on one's own attitudes. Another way to protect one's attitudes is to surround oneself with people who agree with one's attitudes (Caspi \& Herbener, 1990). Thus, the attitude similarity attraction relationship is stronger with greater attitude heritability. Some behavioral geneticists, for example, Scarr and McCartney (1983), have argued that genetic predispositions lead individuals to seek out compatible environments and develop their own environmental niche. These data appear to the first laboratory demonstration (to my knowledge) of the kind of mechanisms associated with such niche selection.

To summarize the argument, attitudes with a biological substrate are relatively difficult and painful to change. However, such attitudes may be jeopardized by the same psychological mechanisms as attitudes with less of a biological basis. Stasis is maintained, at least in part, through psychological protection mechanisms that lead to congenial environments. Undoubtedly, this is not the whole story, but it does explain the results reported here.

\section{Including Heritability in General Theory Testing Designs}

Failing to take heritability into account, particularly in tests of general theories, can be misleading. In the present example, attitudes are not interchangeable. High heritability attitudes behave differently from low heritability attitudes, thereby limiting the generalizability of the standard treatments used in this research.

Admittedly, it is difficult to find many response systems for which there is a known range of heritabilities. However, it might be worthwhile to develop such systems. Including responses measured on the same metric but that differ with respect to heritability in a research design along with a theoreti- 
cally relevant treatment can yield valuable information regarding the generality versus typicality of the treatment.

A treatment is general if it has similar effects over a variety of responses regardless of their heritability. A treatment is typical to the extent that it is representative of the usual variety of situations that subjects generally encounter. Egon Brunswik (1955) stressed the importance of this issue in his related notion of representative design. Including responses that vary in heritability and tracking the magnitude of its interaction with the treatment allows researchers to assess these two aspects of a particular treatment.

Suppose that the heritability of the response moderates, that is, interacts with, the treatment effect such that the treatment is more effective with low heritability attitudes than with high heritability attitudes. The greater the magnitude of this interaction, the less general is the treatment. The treatment is less general because its effectiveness depends on the heritability of the response. At the same time the treatment is more typical. This requires some explanation.

Suppose heritability is estimated on a representative population of people who have been exposed to a representative sample of environments (situations and treatments). Because heritability is the proportion of genetic variance in their responses, I - heritability is an index of the extent to which the response is susceptible to change by typical environmental differences (treatments). If the effectiveness of the present treatment covaries with the complement of heritability, that is, is negatively correlated with heritability, then the treatment is affecting the response like the typical environmental difference. The stronger the association between treatment effectiveness and heritability, the more like the typical situation is the present treatment. ${ }^{9}$

Some treatments may affect all responses equally well. Such treatment would be quite general, but they would not be typical

\footnotetext{
${ }^{9}$ This line of thinking suggests that it is possible to scale treatments in terms of typicality or representativeness without actually sampling situations. If a treatment is representative of typical situational differences, then to the extent that a theoretically relevant response is high in heritability it should be minimally affected by the situation, and if the response is low in heritability, it should be maximally affected by the treatment. An index of treatment typicality then is the (inverse) correlation between the magnitude of the treatment effect and the heritability of the response. (This assumes equally valid and reliable response measures, and no Genotype $\times$ Environment interactions.) It also suggests a new way to gauge the strength of a treatment. Recall that heritability is the ratio of variance due to genes to the sum of variance due to genes and variance due to environments. In principle, then, it is also possible to estimate the proportion of variance due to environments to serve as a kind of standard. Assuming a random sample of subjects, for any particular treatment, for any particular response it is possible to compute a proportion of variance accounted for. Comparing this with the standard would indicate whether the treatment was more or less effective than standard differences in the environment for this particular response. Obviously, a particular treatment may be more or less effective for different responses. Strength of treatment is usually indexed by the raw percentage of variance accounted for. The comparison suggested here may be preferred because it takes account of genetic restrictions relative to typical situational differences.
}

of the kinds of environmental differences persons encounter in their daily lives. Other treatments may be differentially effective across heritability of response, but their effectiveness may be uncorrelated with heritability. Such a treatment is neither general nor typical, but it may be particularly informative, nonetheless. I assume that the heritability of different attitudes reflects different biological processes. Such a treatment might shed light on the particular mechanism underlying the attitude(s) for which the treatment is effective.

\section{Conclusion}

A number of psychological response systems have nontrivial heritabilities. It is recommended that estimates of these components be incorporated into more of researcher's general theory testing. They limit the ease with which responses can be changed and have implications for the generalizability of researchers' theories and the typicality of researchers' experimental treatments.

\section{References}

Abelson, R. P. (1988). Conviction. American Psychologist, 43, 267275.

Aronson, E., \& Carlsmith, J. M. (1968). Experimentation in social psychology. In G. Lindzey \& E. Aronson (Eds.), Handbook of social psychology (2nd ed., Vol. 2, pp. 1-79). Reading, MA: Addison-Wesley.

Arvey, R. D., Bouchard, T. J., Segal, N. L., \& Abraham, L. M. (1989). Job satisfaction: Environmental and genetic components. Journal of Applied Psychology, 74, 187-192.

Asch, S. E. (1956). Studies of independence and conformity: A minority of one against a unanimous majority. Psychological Monographs, $70,416$.

Bandura, A. (1985). Social foundations of thought and action: A social cognitive theory. Englewood Cliffs, NJ: Prentice-Hall.

Bem, D. J. (1972). Self-perception theory. In L. Berkowitz (Ed.), $A d$ vances in experimental social psychology (Vol. 6, pp. 2-62). San Diego, CA: Academic Press.

Bouchard, T. J., \& McGue, M. (1990). Genetic and rearing environmental influences on adult personality: An analysis of adopted twins reared apart. Journal of Personality, 58, 263-292.

Brunswik, E. (1955). Representative design and probabilistic theory in functional psychology. Psychological Review, 62, 193-217.

Byrne, D. (1971). The attraction paradigm. San Diego, CA: Academic Press.

Caspi, A., \& Herbener, E. S. (1990). Continuity and change: Assortative marriage and the consistency of personality in adulthood. Journal of Personality and Social Psychology, 58, 250-258.

Cook, M., \& Mineka, S. (1990). Selective associations in the observational conditioning of fear in rhesus monkeys. Journal of Experimental Psychology: Animal Behavior Processes, 16, 372-389.

Cook, T. D., \& Campbell, D. T. (1979). Quasi-Experimentation. Chicago: Rand McNally.

Dabbs, J. M. (1989). The real man's burden: Testosterone and modern times. Unpublished manuscript. Georgia State University, Atlanta, GA.

Eaves, L. J., Eysenck, H. J., \& Martin, N. G. (1989). Genes, culture and personality: An empirical approach. San Diego, CA: Academic Press.

Eysenck, H. J. (1954). The psychology of politics. New York: Routledge, Chapman \& Hall.

Fazio, R. H., Powell, M. C., \& Williams, C. J. (1989). The role of attitude accessibility in the attitude to behavior process. Journal of Consumer Research, 16, 280-288. 
Fazio, R. H., Sanbonmatsu, D. M., Powell, M. C., \& Kardes, F. R. (1986). On the automatic activation of attitudes. Journal of Personality and Social Psychology, 50, 229-238.

Fazio, R. H., \& Williams, C. J. (1986). Attitude accessibility as a moderator of the attitude-perception and attitude-behavior relations: An investigation of the 1984 presidential election. Journal of Personality and Social Psychology, 51, 505-514.

Feather, N. T. (1975). Factor structure of the conservatism scale. Australian Psychologist, 10, 179-184.

Festinger, L. (1957). A theory of cognitive dissonance. Stanford, CA: Stanford University Press.

Flaste, R. (Ed). (1991). The New York Times book of science literacy: What everyone needs to know from Newton to the knuckle ball. New York: Random House.

Galton, F. (1875). The history of twins as a criterion of the relative powers of nature and nurture. Journal of the Anthropological Institute, 6, 391-406.

Houston, D. A., \& Fazio, R. (1989). Biased processing as a function of attitude accessibility: Making objective judgments subjectively. Social Cognition, 7, 51-66.

Jacobs, R. C., \& Campbell, D. T. (1961). The perpetuation of an arbitrary tradition through several generations of a laboratory microculture. Journal of Abnormal and Social Psychology, 62, 649-658.

Jung, C. G. (1939). The integration of the personality. (S. M. Dell, Trans.). New York: Farrar \& Rinehart.

Kasriel, J., \& Eaves, L. J. (1976). The zygosity of twins: Further evidence on the agreement between diagnosis by blood groups and written questionnaires. Journal of Biosocial Science, 8, 263-266.

Katz, D. (1960). The functional approach to the study of attitudes. Public Opinion Quarterly, 24, 163-204.

Keller, L. M., Bouchard, T. J., Arvey, R. D., Segal, N. L., \& Dawis, R. V. (1992). Work values: Genetic and environmental influences. Journal of Applied Psychology, 77, 79-88.

Kohnstamm, G. A., Bates, J. E., \& Rothbart, M. K. (Eds.). (1989). Temperament and childhood. New York: Wiley.

Latané, B., \& Darley, J. M. (1970). The unresponsive bystander: Why doesn't he help. New York: Appleton-Century-Crofts.

Loehlin, J. C. (1989). Partitioning environmental and genetic contributions to behavioral development. American Psychologist, 44, 12851292.

Loehlin, J. C., \& Nichols, R. C. (1976). Heredity, environment, and personality. Austin: University of Texas Press.

Loehlin, J. C., Willerman, L., \& Horn, J. M. (1988). Human behavior genetics. Annual Review of Psychology, 39, 101-133.

Martin, N. G., Eaves, L. J., Heath, A. R., Jardine, R., Feingold, L. M., \& Eysenck, H. J. (1986). Transmission of social attitudes. Proceedings of the National Academy of Science, 83, 4364-4368.

Martin, N. G., \& Martin, P. G. (1975). The inheritance of scholastic ability in a sample of twins. I. Ascertainment of the sample and diagnosis of zygosity. Annals of Human Genetics, 39, 213-218.

McGuire, W. J. (1969). The nature of attitudes and attitude change. In G. Lindzey \& E. Aronson (Eds.), The handbook of social psychology (2nd ed., Vol. 3, pp. 136-314). Reading, MA: Addison-Wesley.

McGuire, W. J. (1985). Attitudes and attitude change. In G. Lindzey \& E. Aronson (Eds.), Handbook of social psychology (3rd ed., Vol. 2, pp. 233-346). New York: Random House

Milgram, S. (1965). Some conditions of obedience and disobedience to authority. Human Relations, 18, 57-76.

Newcomb, T. M. (1961). The acquaintance process. New York: Holt, Rinehart \& Winston.

Perry, A. (1973). The effect of heredity on attitudes toward alcohol, cigarettes, and coffee. Journal of Applied Psychology, 58, 275-277.

Petty, R., \& Krosnick, J. (Eds.). (in press). Attitude strength: Antecedents and consequences. Hillsdale, $\mathrm{N} \mathrm{J}$ : Erlbaum.

Plomin, R. (1989). Nature and nurture: An introduction to human behavioral genetics. Pacific Grove, CA: Brooks/Cole.
Plomin, R., Corley, R., DeFries, J. C., \& Fulker, D. W. (1990). Individual differences in television viewing in early childhood: Nature as well as nurture. Psychological Science, 1, 371-377.

Plomin, R., \& Nesselrode, J. R. (1990). Behavioral genetics and personality change. Journal of Personality, 58, 191-220.

Plomin, R., \& Rende, R. (1991). Human behavioral genetics. Annual Review of Psychology, 42, 161-190.

Powell, M. C., \& Fazio, R. H.(1984). Attitude accessibility as a function of repeated attitudinal expression. Personality and Social Psychology Bulletin, 10, 139-148.

Pratkanis, A. R., Breckler, S. J., \& Greenwald, A. G. (Eds.). (1989). Attitude structure and function. Hillsdale, NJ: Erlbaum.

Ravich-Scherbo, I. V. (1988). The role of environment and heredity in the development of human personality. Moscow, Union of Soviet Socialist Republics: Pedagogika.

Roberts, C. A., \& Johansson, C. B. (1974). The inheritance of cognitive interest styles among twins. Journal of Vocational Behavior, 4, $237-$ 243.

Rushton, J. P. (1989). Genetic similarity, human altruism, and group selection. Behavioral and Brain Sciences, 12, 503-559.

Rushton, J. P., Fulker, D. W., Neale, M. C., Nias, D. K. B., \& Eysenck, J. J. (1986). Altruism and aggression: The heritability of individual differences. Journal of Personality and Social Psychology, 50, 11921198.

Russell, R. J. H., Wells, P. A., \& Rushton, J. P. (1985). Evidence for genetic similarity detection in human marriage. Ethology and Sociobiology, 6, 183-187.

Scarr, S. (1981). The transmission of authoritarian attitudes in families: Genetic resemblance in social-political attitudes? In S. Scarr (Ed), Race, social class, and individual differences (pp. 399-427). Hillsdale, NJ: Erlbaum.

Scarr, S., \& McCartney, K. (1983). How people make their own environments: A theory of genotype $\rightarrow$ environment effects. Child Development, 54, 424-435.

Scarr, S., \& Weinberg, R. A. (1978, April). Attitudes, interests, and IQ. Human Nature, pp. 29-36.

Schachter, S., Kozlowski, L. T., \& Silverstein, B. (1977). Effects of urinary $\mathrm{pH}$ on cigarette smoking. Journal of Experimental Psychology: General, 106, 13-19.

Sherif, M. (1937). An experimental approach to the study of attitudes. Sociometry, 1, 90-98.

Simon, H. A. (1954). Spurious correlation: A causal interpretation. Journal of the American Statistical Association, 49, 467-479.

Smith, M. B., Bruner, J. S., \& White, R. W. (1956). Opinions and personality. New York: Wiley.

Snyderman, M., \& Rothman, S. (1987). Survey of expert opinion on intelligence and aptitude testing. American Psychologist, 42, 137144.

Tellegen, A., Lykken, D. T., Bouchard, T. J., Wilcox, K., Segal, N. L., \& Rich, S. (1988). Personality similarity in twins reared apart and together. Journal of Personality and Social Psychology, 54, 1031-1039.

Tesser, A., \& Shaffer, D. (1990). Attitudes and attitude change. In M. Rosenzweig \& L. Porter (Eds.), Annual review of psychology (Vol. 41, pp. 479-523). Palo Alto, CA: Annual Reviews.

Waller, N. G., Kojetin, B. A., Bouchard, T. J., Jr., Lykken, D. T., \& Tellegen, A. (1990). Genetic and environmental influences on religious interests, attitudes and values: A study of twins reared apart and together. Psychological Science, 1, 138-142.

Wilson, G. D., \& Patterson, J. R. (1968). A new conservatism scale. British Journal of Social and Clinical Psychology, 7, 264-269.

Received November 26, 1991

Revision received June 8, 1992

Accepted June 22, 1992 